\title{
XXVII Festival Internacional de Teatro Hispano de Miami
}

\section{Luis F. González-Cruz}

El vigésimo séptimo Festival Internacional de Teatro Hispano de Miami, del 12 al 29 de julio de 2012 (dirigido por Mario Ernesto Sánchez; patrocinado por Teatro Avante, American Airlines y otras agrupaciones), rindió tributo al teatro latino que se produce en los Estados Unidos. Participaron compañías de Estados Unidos, Argentina, Ecuador, España y México. El programa educativo, dirigido por la Dra. Beatriz J. Rizk, incluyó coloquios después de las representaciones, talleres, presentaciones de libros, lecturas dramatizadas dirigidas por la Dra. Rizk (de Julio Matas: El cambio, Tonos y Juego de damas; de Luis Enrique Gutiérrez Ortiz Monasterio: Las chicas del 3.5 Floppies; de Virgilio Piñera: Estudio en blanco y negro y Los siervos) y un estupendo congreso en el cual participaron notables estudiosos del teatro. Los afiches del Festival fueron diseñados por Roberto Silva (puertorriqueño) y Armando Tejuca (cubano americano); el Premio a una Vida de Dedicación a las Artes Escénicas se otorgó a Teresa María Rojas (cubana).

Short Eyes ("Urban Theatre Movement", Los Ángeles, EEUU; autor: Miguel Piñero; dirección: Julián Acosta) muestra a un grupo de reos en el patio interior de una prisión que se interrelacionan según sus diferentes intereses. Predomina el tema del sexo, tanto en el recuento de experiencias heterosexuales, como en escenas de carácter homosexual. Un nuevo preso, acusado de ser violador de niñas, viene a unirse al grupo: su crimen es censurado por los demás, quienes al final le dan muerte. Lo que vemos y oímos es la descarnada realidad de la vida entre rejas. La obra queda marcada por un crudo realismo, carente de artificios. Lo que se ofrece al espectador, a lo largo, es una visión superficial, heterogénea, de aquel conglomerado de seres violentos que viene a configurar un collage multicultural de vicios humanos. La calidad de las actuaciones permitía olvidarnos de que eran actores y no presidiarios los sujetos que veíamos en escena. Infieles ("La Compañía Pro- 
meteo", Teatro Prometeo del Miami-Dade College, Miami, EEUU; autor: Marco Antonio de la Parra; dirección: Ernest Figueroa) se destacó por las interpretaciones de Hannah Ghelman, Cristina Ferrari, Boris Roa y Guillermo Pérez, quienes dan auténtica vida escénica a dos matrimonios resquebrajados por la infidelidad de uno de los cónyuges, lo que desencadena los desastres inevitables de los cuatro. La acción, en Chile, durante la época de Augusto Pinochet, pone énfasis en los males del régimen y de una sociedad de consumo a los que atribuye parcialmente el fracaso de estos seres, quienes, bien mirado, son los únicos culpables de sus frustraciones y su ruina. La escenografía de Jorge Noa y Pedro Balmaseda resultó hermosa e inteligente: utilizaron la cama como símbolo de la infidelidad y se valieron de tres lechos estrechos, altos y dinámicos, que se cambiaban de lugar según las necesidades de la trama; toda la parte superior del escenario figuraba los cabezales de grandes camas: de ellos colgaban flotantes cortinas semitransparentes. Lo más notable fue la dirección integral de Ernest Figueroa; aprovechó cada detalle del texto para convertir un tema muy trillado en una obra de arte: sus soluciones originales y el movimiento perpetuo de los personajes no permitieron que decayera ni un instante el interés del espectador. El hilo argumental de Solitude ("Latino Theater Company", Los Ángeles, EEUU; autora: Evelina Fernández; dirección: José Luis Valenzuela) es tenue: la madre cría sola a su hijo, quien, a los veinticinco años de edad, conoce a su padre en el funeral de la madre de éste, cuando es demasiado tarde para reconciliaciones. Las meditaciones de los personajes revelan zonas oscuras de cada cual: frustraciones, remordimientos y, en el caso de la madre sola, el orgullo del deber bien cumplido. Los diversos temas discutidos se encadenan con momentos en que bailan todos al compás de música de mambo. El tono desenfadado y los toques de humor dan ligereza a la obra. El montaje novedoso despoja el argumento de lo que pueda tener de trillado o predecible. Las actuaciones y el acompañamiento musical del violonchelista Semyon Kobialka fueron de primer orden. El Día Internacional del Niño contó con talleres de actuación, baile, música, danza, marionetas y artesanía. Se presentaron dos comedias infantiles-Yo la llamo Rusita Rojas ("Teatro Doble", Miami, EEUU; autora: Cristina Ferrari; dirección: Neher Jacqueline Briceño) y El encuentro de Juan Bobo y Pedro Animal ("Teatro Sea", Nueva York, EEUU; escrita y dirigida por Manuel A. Morán) - que complacieron a chicos y adultos por igual.

En esencia, el cine es movimiento y el teatro, actuación. Una interpretación como la de María Merlino en Nada del amor me produce envidia ("Flor de un día", Buenos Aires, Argentina) bastaría para justificar la existencia de 
este Festival y del teatro mismo. Cada movimiento, palabra, pausa, canción, mostró el virtuosismo de esta estrella. A esto se añadió la acertada dirección de Diego Lerman y el texto fresco y artístico de Santiago Loza. La pieza trata temas profundos a través de las experiencias de una costurera que confecciona un vestido para Libertad Lamarque, del cual se enamora, al verlo en el taller de la obrera, Eva Duarte de Perón. En la disyuntiva de qué hacer con la prenda de vestir, a cuál de las dos eminentes mujeres complacer, decide no dárselo a ninguna y convertirse ella en reina, poniéndoselo, para bailar así vestida, enloquecida por el estremecimiento que ha tenido su vida, y finalmente darle fuego a su hogar y a sí misma. El encuentro con las dos grandes figuras viene a ser para la costurera el evento extraordinario que cambiará su vida. Es lo extraordinario lo que esperamos siempre. En algunos casos nunca ocurre; en otros, acontece a veces cuando no estamos preparados. Esto último es lo que sucede a la costurera, quien sucumbe en el momento máximo de su plenitud profesional. Pero ese instante, el que le da por primera vez la oportunidad de decidir, de ser ella quien escoja entre Libertad y Eva, ese poder del que de pronto se ve dotada, la posibilidad de pertenecer al grupo humano de "los que deciden" y no al de "los que acatan", le da la felicidad suprema. "La Máquina de Teatro", de la Ciudad de México, trajo Malinche / Malinches (escrita y dirigida por Juliana Faesler, en colaboración con la Compañía). Cinco actores (cuatro mujeres y un hombre) interpretan una multitud de personajes de ambos géneros; los femeninos representan reencarnaciones de Malinche, la concubina india de Hernán Cortés. Las "Malinches" que muestra Faesler son mujeres mexicanas que dan detalles de sus vidas y circunstancias dentro de una sociedad que ha sido moldeada por su pasado histórico. También se cuenta o escenifica, a jirones, la propia historia de la verdadera Malinche. La eficiente dirección, el dinamismo con que está movida la acción y la original amalgama de utilería hábilmente manejada - al final se llena el escenario de unas alegóricas, gigantescas matas de maíz, de donde proviene el alimento que propulsó el desarrollo de estas culturas precolombinas - hicieron de éste un espectáculo placentero y visualmente atractivo. En Aviones de papel ("Zerocompañía", Nueva York, EEUU; autor: Diana Chery-Ramírez; dirección: Aminta De Lara), las líneas blancas sobre el piso negro del escenario crean sendas que llevan a dos departamentos conectados por una endeble pared, más otras que conducen a la calle. El fino tabique - que se insinúa mediante una franja divisoria formada por numerosos avioncitos de papel alineadosfracciona lo que antes había sido una sola residencia y permite que pasen a través de él los ruidos producidos por Beatriz, interfiriendo con la paz que 
desea Diego, el nuevo inquilino del espacio adyacente al de ella. Se producen entre los jóvenes varios altercados. En un momento de furia, causado por los perturbadores sonidos, Diego despedaza la pared y queda rota la frontera que los separa. Así, logran conocerse mejor y luego amarse. Él siempre termina rechazándola. Finalmente reconstruye la pared para dar término a un enlace que no puede llegar a ninguna plenitud, pues tiene una enfermedad incurable y espera la muerte. No hay nada en esta mise en scène que resulte melodramático. Todo se resuelve con delicadas sugerencias y las interpretaciones substanciales de Carlos Alberto Valencia y Diana Chery-Ramírez. André y Dorine ("Kulunka Teatro", Hernani, País Vasco, España; creadores: Garbiñe Insausti, José Dault, Iñaki Rikarte, Rolando San Martín y Edu Cárcamo; dirección: Iñaki Rikarte) rompe los moldes del teatro convencional: es la historia de un viejo matrimonio - él escritor, ella violonchelista - que se enfrenta a la enfermedad de Alzheimer de la mujer. Los personajes actúan con unos grandes mascarones que les cubren completamente las cabezas, grotescos pero expresivos, de habilidosa confección. Se reconstruyen con el pensamiento-y los vemos escenificados-momentos claves de la juventud de estos dos seres. A pesar de no haber palabras, existe un contexto que llega sin empañarse al espectador, conmoviéndolo. Lo cómico y lo dramático se mezclan armónicamente. No se descuidó un solo detalle en este singular y excelente espectáculo. La flor de la Chukirawa ("Contraelviento Teatro", Quito, Ecuador; escrita y dirigida por Patricio Vallejo Aristizábal) enfrenta a dos mujeres, una reportera de televisión (también ángel mensajero) y una madre campesina que ha perdido a su hijo - quien aparece en escena en forma de espíritu o ángel — en la guerra de Irak, luchando con las fuerzas del ejército estadounidense. Se plantean problemas actuales de la sociedad ecuatoriana y se critica a los Estados Unidos, que ha enlistado como soldado a un inmigrante ecuatoriano recién llegado, quien no conoce la lengua del país por el que lucha, no sabe su himno nacional y sólo ha servido de "carne de cañón". Se da gran importancia a los movimientos físicos - de belleza plástica-y a las modulaciones vocales de los actores. La flor de la chukirawa es símbolo de esperanza y fracaso a la vez: aunque se regala para dar a su recipiente buena suerte, es dura y está llena de espinas. La madre, representante de su raza, porta al final la flor, dando a entender la imposibilidad del milagro que devuelva a su gente al estado original de pureza, en armonía con su primitivo entorno. En la adaptación de El no presentada por "Teatro Avante" (Miami, EEUU; autor: Virgilio Piñera; versión libre de Gilda Santana; dirección: Mario Ernesto Sánchez), los novios (interpretados por Julio Rodríguez ["Vicente"] 
y Maribel Barrios ["Emilia"]) envejecen obstinados en mantener la relación platónicamente, sin contraer matrimonio, por haber hallado la felicidad pasando juntos varias horas cada noche sentados en sus sillones, ella tejiendo y él haciendo crucigramas. Los padres (interpretados por Gerardo Riverón e Isabel Moreno), al ver que pasan los años sin que haya boda, ya que la hija y su novio siempre dicen "no" al enlace, sucumben a causa de la angustia causada por la inflexible negativa de Emilia y Vicente. Los vecinos irrumpen en la casa para hostigar entonces a la pareja e instigarlos a que se casen: les prometen venir día tras día para seguir insistiendo hasta que se efectúe el matrimonio. Los novios envejecidos deciden no luchar más por su causa y se encaminan a la cocina para abrir las llaves del gas del fogón y suicidarse, pero cambian de idea, se dan vuelta y vuelven a sus sillones, donde se mecen frenéticamente mientras se produce el apagón. El problema en sí nunca habrá de resolverse. Se hacen evidentes aquí rasgos comunes de la naturaleza humana: la lucha por el poder; la conflictiva realidad de los novios que son tanto víctimas como victimarios; el derecho que tiene cada cual a disentir y el conflicto que existe entre el modo de pensar de una generación y la que le sigue. Notables fueron: la espléndida dirección de Sánchez; el diseño de luces del propio Sánchez y Ernesto Padilla; la música de Mike Porcel; las actuaciones estelares de Barrios, Rodríguez, Riverón y la superlativa de Isabel Moreno, quien tuvo momentos brillantes (entre otros, el de la escena de la locura de la madre) y la portentosa escenografía de Jorge Noa y Pedro Balmaseda: puesto que Emilia ha pasado la vida entera en su sillón tejiendo mantas, manteles, cubrecamas, cortinas, ropa, etc., todo el decorado ha sido cubierto por estos paños que representan el único fruto de una existencia baldía. Con la puesta en escena de El no, la más notoria del Festival, concluyó este importante evento que esperamos con avidez cada verano en Miami.

\section{Penn State University}

